\title{
An Analysis of the Concept and Practices of Sustainable Development among Postgraduate Students in District Lahore
}

\author{
Saiqa Yameen \\ The Smart School (TSS), Lahore, Pakistan
}

\begin{abstract}
Sustainable development captured the attention of public and private authorities worldwide. Pakistan also started contributing towards sustainable development since 1992. This paper aimed to analyze the concept and practices of sustainable development among postgraduates in district Lahore, Pakistan. The purpose of the study was to assess the extent of awareness among postgraduates; the stakeholders to ensure the sustainability in the near future. Moreover, reviewing their practices regarding sustainable development. Two stage random sampling technique was used and therefore one hundred and fifty students were taken as a sample from six postgraduate institutions of Lahore. Two self-structured questionnaires were administered to collect the data. Likert scale in Questionnaire "A" was used to assess the extent of awareness; questionnaire "B" with options yes/no was used to check the practices regarding sustainable development. Data were analyzed by using different statistical techniques i.e. frequency distribution, independent samples t-test, one-way ANOVA, Pearson correlation was applied to find the relationship among the variables. Findings showed that neither the extent of awareness is very high nor the practices are in the favor of sustainable development but there exists the positive significant relationship between awareness and practices. The paper proposed that being a developing country, sustenance is exigent and emergent facet of Pakistan's future sustainable development. It is recommended that to ensure sustainability; ESD should be made an essential component of all educational programs at post graduate level.
\end{abstract}

Keywords: Analysis, Concept, Practices, Sustainable development, Postgraduate Students, Lahore

DOI: $10.7176 / \mathrm{DCS} / 9-10-04$

Publication date:October $31^{\text {st }} 2019$

\section{Introduction}

The idea of the sustainability was risen into 1713 when Carlowitz altered his book on backwoods sciences. Sustainable development is to meet the essentials of present without imperiling the capability of bay and by generations "Brundtland Report"1987, p43. Its prosperity confines from the hidden contemplations on the present issues of menfolk affirmed around then, improving worry over decrease of common assets and financial development at the use of ecological worth. While sustenance, we mean the essential products and offices, for example, foodstuff, apparel and safe house that are indispensable to withstand and normal individual at the unadorned least level of living. The Government of Pakistan, 1992 adopted the "National Conservation Strategy" as an official policy document. Adopting sustainable practices and sensible policies, we mean that project activity should be economically viable, socially acceptable and environment friendly.

Clayton and Bass, (2002) stressed on the request of sustainable advancement. Every nation should have received an approach custom fitted to its own needs. There is an enduring bulk of prose on sustainable development. The most eminent international reports on the theme are those of the World Commission on Environment and Development (the Brundtland Commission) (WCED, 1987) and Agenda 21 (UNCED, 1992). There are numerous meanings of Sustainable development, yet most extreme famous and satisfactory definition has augmented in the Brundtland Commission of the United Nations 1987 i.e. manageable improvement is to experience the necessities of the contemporary without arranging the bent of up and coming companions to meet their own necessities. In a document "Science for a Sustainable Future", 2012 it is stated sustainable development is to make and maintain conditions under which people and nature can exist in imaginative congruity, which permit satisfying the social, monetary, and different requests of present and set up a future generation.

Millennium Development goals presented in Millennium Summit of United Nations 2000 are hall mark to sustainability and offered a foundation for the sustainable development, especially the 7th one i.e. To Ensure environmental sustainability. The eight Millennium Development targets were to: Eradicate extreme poverty and hunger, achieve universal primary education, Promote gender equality and empower women, Reduce child mortality, Improve maternal health, Acute HIV/AIDS, malaria and other lethal diseases, Ensure environmental sustainability, Promote a global partnership for development but there is a range of pressing and interrelated challenges suggested by Clayton \& Bass, 2002 to achieve sustainable development in developing countries i.e. Economic Disparity and Political Instability, Extreme Poverty, Disease, Marginalization, Population growth, Urbanization, Climate Change, Nitrogen Loading, Natural Resources Deterioration, Loss of Diversity, Contamination, Turning Water Scarcity, Other Urban problems, Interaction between Environmental, Social and Economic Problems.

A number of models can be used to present the concept of sustainable development i.e. Prism model, egg 
model etc. Simply the most popular among all is the three legged stool model which was suggested by Flint. R.W. \& Houser. W.L. In this model each leg represents one of each of the vital components-Economic liveliness, Ecological Integrity and Social Equity. If one of the leg removed the stool couldn't stand. Underlining the significance of all three legs to upholding the upright position of stool as equally all three components are essential to the satisfying of sustainable targets. Living a Sustainable Lifestyle for Our Children's Children By R. Warren Flint, W. L. Houser 2001

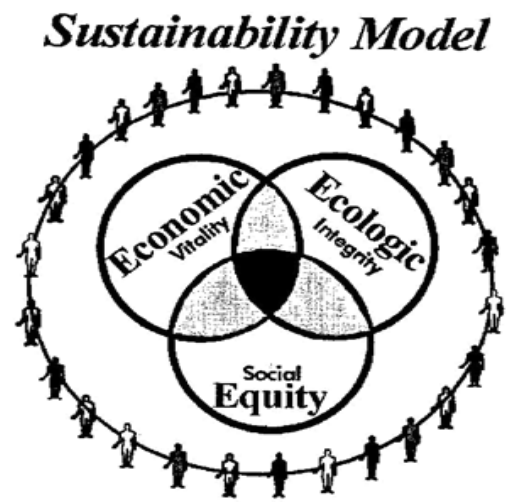

Sustainable growth is a huge term that comprises upon different areas of environment protection, economic and social growth. These areas are the creations of the sustainable evolution. Sustainable growth is often reported as being built on three equally important foundations or pillars. These three are the vital pillars of the sustainable development and are strongly interrelated for the healthier and secure environment and integrated in such a manner that an equilibrium is needed for the proper working of the global cycles.

Sustainability doesn't emphasises on environmental, social, economical perspective solely but seek to find out harmony and equilibrium between the triplet is the name of sustainability. Karatzoglu, 2012 says that he holistic approach, esential to achive the transition between three pillars of sustaiable development and univerisites have been active contributors towards the attainment of sustainable development.

Importance of sustainable development can be realized form the following facts:

Environmental sustainability is a key for human health and survival. Practical utilization of assets and ecological concern has turned out to be progressively vital to address the disturbing states of environmental change and if are not tended to, this will bring about high social and monetary cost. It includes: climate change, quality air; the tone of urban air is so pathetic that it controls the quantity of suspended particles (2- 3.5) times higher than the safe limit (Environment, 2014, p. 263), proper water and sanitation system as per Pakistan Council of Research in Water Resources (PCRWR), the heft of the populace in the provincial region is presented to the dangers of drinking risky and sullied water from both surface and ground water sources, efficient waste management, measures to increase forest, eradicating threats to bio diversity. Genuine dangers to wild landraces of developed harvests have been exhibited by the passage of high return assortments, agribusiness extension and dam development, they all prompt to the debasement of biodiversity assets Baig and Subaiee (2011). Sfakianak (2015) emphasized on resource efficient construction to satisfy the objectives of economic development aligning with the environment.

The word refers to the social characteristics of living creatures, including Flora, Fauna and populations of human organisms' social sustainability encompasses: Poverty Reduction, Gender Equality and women Empowerment, Culture Preservation; few things in human lifetime are more powerful than ideas and concepts, and culture is one of the most influential in all walkways of life (Dessein, Soini, Fairclough \& Horlings, 2015). culture takes on its evolutionary, holistic and transformative role, supplying a novel paradigm to the question of sustainable development (Soini \& Birkeland, 2014). 


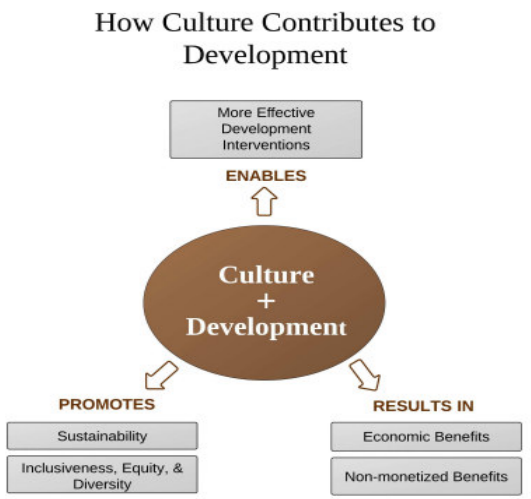

Source: http://www.un.org/millenniumgoals/pdf/Think\%20Pieces/2 culture.pdf

Adam Smith made the idea of the political economy. Smith's ideal market society would now be guarding nature and our social frameworks for payment. The concepts that are engraved in it are: green productions, economic development.

Actions are louder than the words. Sustainable Practices under the umbrella of improvement are displayed as takes after:

\section{Environment:}

- Know what is renewable and can be utilized in valuable and conservative ways.

- Designate "no-assemble", "no-improvement" zones with open strategies.

- Know what existing strategies (neighborhood, region, government) identify with the normal assets in your district.

\section{Socio-Cultural:}

- To know the historical backdrop of the station.

- Rejoice the positives of social history.

- Describe the fate of a sprouting group; an imaginative, dynamic culture

- Focus forthcoming shots; lessen negative considering.

- Seek out coordinated effort from and with adjoined groups.

Innovations/Technology:

- Encourage and put resources into innovations that will spare assets, time, cash, or create new open doors.

- Eschew advancements that are not useful and that might be inefficient of different assets over the long haul.

- Reconsider low-tech, more seasoned advances for new applications to new issues.

- Inspire and upgrade interests in new abilities that have dependable, positive ramifications for the entire group.

- Evaluate all infrastructural choices to attempt various outcomes with single framework costs.

\section{Financial aspects}

- Assess all open costs on both a first-cost and life-cycle cost establishment.

- Pursue and adjust of proportionate costs, based upon appropriate proportions of the individuals who will profit by an open resource.

- Be watchful of convincing future eras of group inhabitants to consumptions that may not raise their private area or their spirits.

- Pursue open/private associations in every single societal venture.

This study may be helpful for the stakeholders. Development without distraction is the basic requirement of the sustainable development. The focus of the study will be on the assessment of the concept of awareness in students at postgraduate level and their practices regarding sustainable development. This will say that what kind of skills and knowledge is imparted by educational institutions in the environmentalists, social scientists and economists and it is the ultimate responsibility of the educational institutions to incorporate the concept of sustainability among postgraduates for the atmospheric peace, social harmony and economic sustenance. This study will provide the extent of awareness of sustainable development among the educated cultivation and whether their practices contribute to ensure sustainability.

\section{Statement of the research topic}

Sustainable development is an emerging concept in the third world. Sustainability s an essential and vital aspect to effectiveness. The study designed to analyze "The Concept and Practices of Sustainable Development among Postgraduate Students in Lahore" 


\section{Objectives of the study}

Following were the objectives formulated for the study to:

- measure the level of awareness of postgraduate's regarding sustainable development.

- $\quad$ check the practices of sustainable development among postgraduates.

- find a relationship between the awareness and practices regarding sustainable development.

\section{Research Questions}

1. To what extent students are aware of sustainable development at postgraduate level?

2. Do the female students more aware regarding sustainable development on the basis of degree program?

3. Does semester, contribute to aware the pupils at postgraduate level?

4. Is there significant difference regarding practices of sustainable development on the basis of gender?

5. Whether the degree program and semester, contribute to the practices of sustainable development?

6. Does semester add to improve the practices of postgraduates regarding sustainable development?

7. Is there a relationship exists between awareness and practices regarding sustainable development?

\section{Methodology}

\section{Research Design}

The descriptive method was used to analyze the concept and practices of postgraduates regarding sustainable development. Cross sectional survey was used as research design and Pearson correlation analysis to see the strength of correlation between the extent of awareness and practices regarding sustainable development. Descriptive research involves collecting data from postgraduates of six institutions of Lahore city in order to draw findings and generalizing the results.

\section{Participants}

Population of the study were the post graduate students of the six institutions of the Lahore city; namely University of the Punjab, Government College University,

University of the Education (Bank and Lower Mall road Campus), University of engineering and technology and Government postgraduate college for women Samanabad Lahore. Convenient sampling technique was used to collect data as whoever happened to be available in the summer vacations.

\section{Instrumentation}

The research instrument used for the study were two questionnaires; questionnaire " $\mathrm{A}$ " was with Likert scale having 5 alternative ratings i.e. 5 for high awareness and 1 for least awareness to measure the extent of awareness among postgraduates. Questionnaire "B" was used to check the practices regarding sustainable development with yes/ no option. Moreover, demographic information was also collected.

Validity and reliability of the instrument

The tool was validated by experts. Reliability of the instrument is given as follows:

\begin{tabular}{llll}
\hline Scale & & No. of Items N & $\begin{array}{l}\text { Charonbac's } \\
\text { Alpha }\end{array}$ \\
\hline $\begin{array}{l}\text { Awareness \& Practices } \\
\text { Sustainable development }\end{array}$ & regarding & 29 & .723 \\
\hline
\end{tabular}

Reliability of the tool consisting upon 29 items was measured by using SPSS and the Charonbac's alpha coefficient was 0.723 that shows a good reliability among items.

\section{Data Analysis and interpretation}

Analysis and interpretation of data is the heart of research work. Data collected from the hard toils analyzed using descriptive and inferential statistics. 
Table 1

Division of participants on the basis of gender, disciplines \& semester

\begin{tabular}{lll}
\hline Mug Shot of Respondents & Frequency $(\boldsymbol{f})$ & Percentage (\%) \\
\hline Gender: & 59 & 39.3 \\
Male & 91 & 60.7 \\
Female & & \\
Disciplines: & 44 & 29.3 \\
Pure Science & 88 & 58.7 \\
Social Science & 18 & 12.0 \\
Applied Sciences & & \\
Semester: & 76 & 50.7 \\
Junior & 73 & 48.7 \\
Senior & & \\
\hline
\end{tabular}

The number of participants for the present study was 150, 59 (39.3\%) were Male whereas 60.7\% were Female. In terms of disciplines, the total of $44(29.3 \%)$ were from Pure sciences, 88 (58.0 \%) of Social Sciences and 18 (12.0\%) representing Applied Sciences.

In terms of semester 76 participant were junior (50.7\%) as they are in earlier semester of the degree programs and 73 (48.7) were senior as they are studying in late semester of their degree programs.

Table 2

Extent of Awareness towards Sustainable Development on the Basis of Gender and Semester

\begin{tabular}{|c|c|c|c|c|c|c|c|}
\hline Variable & & $(\mathrm{N})$ & SD & Mean & t-Value & $d f$. & p-value \\
\hline \multirow{2}{*}{ Gender } & Male & 59 & 48.3390 & 7.69149 & \multirow[t]{2}{*}{-3.282} & \multirow[t]{2}{*}{148} & \multirow[t]{2}{*}{.001} \\
\hline & Female & 91 & 52.8571 & & & & \\
\hline \multirow{2}{*}{ Semester } & Junior & 76 & 50.3947 & 8.35237 & \multirow[t]{2}{*}{-.972} & \multirow[t]{2}{*}{147} & \multirow[t]{2}{*}{.333} \\
\hline & Senior & 73 & 51.7534 & 8.71107 & & & \\
\hline
\end{tabular}

Significant at level $\mathrm{p}<0.05$

In this study $59(39.3 \%)$ were Male whereas $60.7 \%$ were Female. The t-test showed that there is a significant difference $(\mathrm{p}<.05)$ between the mean scores of male (48.3390) and females $(52.8571)$ with the $t$-value of -3.282 and $d f$. 148. Females are comparatively more aware as compare to males. As far as the semester is concerned it is divided into two categories junior (76) and senior (73). Students' t-test was applied and it is evident it doesn't put significant difference $(\mathrm{p}>.05)$. The t-value is $-.972 d f$. 147.

Table 3

Practices Regarding Sustainable Development on the Basis of Gender and Semester

\begin{tabular}{llllllll}
\hline Variable & & $\mathrm{N}$ & $\mathrm{SD}$ & Mean & t-Value & $d f$. & p-value \\
& & & & & & \\
\multirow{2}{*}{ Gender } & Male & 59 & 9.7119 & 2.23646 & -2.412 & 148 & .017 \\
& Female & 91 & 10.6484 & 2.37755 & & & .608 \\
\multirow{2}{*}{ Semester } & Junior & 76 & 10.1579 & 2.30970 & -5.14 & 147 & \\
& Senior & 73 & 10.3562 & 2.40006 & & & \\
\hline
\end{tabular}

Significant at level $\mathrm{p}<0.05$

The table above demonstrates the practices of participants regarding sustainable development. For comparison purpose independent sample t-test was applied. Results shows that the difference the found on the basis of gender is significant $(\mathrm{p}<.05)$ with the t-value -2.412 and practices of females $(10.6484)$ are more sustainable as compare to males (9.7119). Moreover, there is no significant difference ( $p>.05)$ found on the basis of semester. The $d f$. Is 147 and the t-value is -5.14 . 
Table 4

ANOVA-To Measure the Awareness and practices on the Basis of Degree Program

\begin{tabular}{|c|c|c|c|c|c|c|}
\hline & $\begin{array}{l}\begin{array}{l}\text { Sources } \\
\text { variation }\end{array} \text { of } \\
\end{array}$ & Sum of Squares & Mean Square & $\mathrm{F}$ & $d f$ & Sig. \\
\hline \multirow[t]{2}{*}{ Awareness } & $\begin{array}{l}\text { Between } \\
\text { Groups }\end{array}$ & 247.622 & 123.811 & 1.729 & 2 & .181 \\
\hline & Within Groups & 10525.418 & 71.601 & & 147 & \\
\hline \multirow[t]{2}{*}{ Practices } & $\begin{array}{l}\text { Between } \\
\text { Groups }\end{array}$ & 2.694 & .245 & .617 & 11 & .812 \\
\hline & Within Groups & 54.799 & .397 & & 138 & \\
\hline
\end{tabular}

Significant at level $\mathrm{p}<0.05$

Analysis of variance was applied to measure the difference in the mean scores on awareness and practices regarding sustainable development on the basis of degree program, it is evident that no significant difference $(p>.05)$ was found on the basis of degree program.

Table 5

Correlation: relation between concept/awareness and practices of postgraduate's regarding sustainable development

\begin{tabular}{llll}
\hline Variable & $\mathrm{N}$ & R-value & Sig \\
\hline Sum Awareness & 150 & .356 & .000 \\
\hline Sum Practices & & &
\end{tabular}

Significant at level $\mathrm{p}<0.05$

The above table indicated that a positive significant relationships $(\mathrm{p}<.05)$ exists between the awareness and the practices of the sustainable development at postgraduate level. It means that the more the students are aware about sustainable development, the more they practice

\section{Summary and Findings}

In the light of data analysis, findings were drawn. Following findings are drawn from the analysis of data.

1. The statistic results show that total participants for the present study were 150 students out of them 59 (39.3\%) were male whereas $60.7 \%$ were female. The degree Programs were divided into three categories; results revealed that out of 150 participants 44 (29.3\%) were of natural sciences, 88 (58.0 \%) of Social Sciences and $18(12.0 \%)$ enrolled in Applied Sciences. Percentage method was applied to divide the participants. They responded $100 \%$ against the demographic variable. It has been observed that 76 participants were junior (50.7\%) as they are in earlier semester of the degree programs and 73 were senior as they are studying in late semester of their degree programs.

2. Independent sample t-test was applied to compare the level of awareness regarding sustainable development the mean scores. Results show that there is a significant difference $(p<.05)$ between the mean scores of male (48.3390) and females (52.8571) with the t-value of -3.282 and $d f$. 148. Females are comparatively more aware as compare to males. Comparison of awareness regarding sustainable development on the basis of semester was done by dividing the variable into two categories i.e. junior and senior. T-test was applied to accomplish the research purpose. It is evident from the analysis there is no significant difference ( $\mathrm{p}>.05$ ) was found and the t-value is $-.972 d f .147$.

3. For comparison purpose independent sample t-test was applied. Results shows that the difference the found on the basis of gender is significant $(\mathrm{p}<.05)$ with the t-value -2.412 . Moreover, practices of females (10.6484) are more sustainable as compare to males (9.7119). Table demonstrates the Comparison of sustainable development practices on the basis of semesters divided into two categories junior (76) and senior (73). T-test was applied and it is evident there is no significant difference ( $\mathrm{p}>.05)$. The $d f$. Is 147 and the $\mathrm{t}$-value is -5.14 .

4. Analysis of variance was applied to measure impact of degree program on the level of awareness and it was found that the students of different degree program don't put the significant role; i.e. ( $p>.05)$ in their awareness regarding sustainable development. Statistical analysis show that no significant difference ( $p>$.05) was found on the basis of degree program regarding practices of sustainable development. The degree of freedom between groups is 11 and the within groups is 138 .

5. A positive significant relation $(\mathrm{p}<.05)$ was found between awareness and practice

\section{Conclusion}

It was concluded from the finding that there is significant difference on the basis of gender and females are comparatively more aware as compare to males. The degree program don not puts the significant impact to aware 
the students regarding sustainable development. Finding reveals that no eloquent difference related to awareness; was found on the basis of semester among postgraduate students. Practices apropos of sustainable development was measured and it is concluded that practices of females add more as compare to males to the sustainable development. It is enclosed on the basis of results that degree program is not putting the significant impact on the practices regarding sustainable development. Comparison of practices regarding sustainable development was wrapped up with the statement; that semester is not contributing towards sustainable development. The essence of the study is that the more students have awareness regarding sustainable development the more they will practice such habits that sustain the atmospheric peace.

\section{Recommendations}

In the light of findings and conclusions following recommendations are proposed.

1. Education for Sustainable Development should be an essential component of all integrated courses being taught at postgraduate level.

2. Seminars should be arranged to keep the students aware regarding sustainable development.

3. Workshops and trainings should be arranged to demonstrate the mini practices regarding sustainable development.

4. Trainings ought to be arranged for the teachers as well so that they incorporate the theoretical and practical knowledge into students.

5. Policy maker should give a meaningful corner to the sustainability and integrity.

6. Awareness and practice are two sides of a coin. So maximum awareness ensured so they could turn into practice. 